\title{
The BRICS need to turn to policies instead of politics!
}

\author{
By Sven Grimm, \\ Director, Centre for Chinese Studies, Stellenbosch University
}

The annual BRICS (Brazil, Russia, India, China and South Africa) summit is coming up on 28/29 March, this time in India, under the slogan 'BRICS Partnership for Global Stability, Security and Prosperity'. This list of good things in the world is non-descript. Well, such is summit culture. Discussions can go one way or the other on the respective sizes of the economies and their respective roles in the world. Yet, what is the group's role and position, a year since their enlargement with South Africa - or asked differently: is there a single understanding and one role that the debate is about?

The ringing words in the title of this summit are illustrative either of huge ambitions or of a lack of depth to the agenda. It is most likely the latter. The BRICS are clearly not an international organisation and thus have a loosely defined agenda. But the aspiration is more than just another global summit. Public-relations are an important part of the event, so some semantic difficulties will persist while presenting a somewhat coherent agenda. Yet, expectation management is also part of the task and here the group fails.

At the moment, the BRICS are rather following the - somewhat outdated - summit culture of the G8, while, in fact, the emerging powers' club is not only an event for heads of state. Experts' rounds are taking place between academics and think tankers from BRICS countries, not least so to prepare the summits. In the best of circumstances, the BRICS are a learning forum (how do you do what we need to do, too?) and, at the least, they are a meeting place to establish contacts between business leaders. Both are useful purposes. The fact that they will (a) not safe the world all by themselves and (b) are not without alternatives does not reduce the value of these rounds. Yet, more - and more structured - dialogue could happen.

If the BRICS want to become more meaningful, they could establish mechanisms that go beyond the 'fireplace talks' and get working groups together on issues, not least so: do some peer reviewing of economic performance, energy policies, education and training efforts, policies around food security or other pertinent issues for members. Global international finance and the reform of global financial governance is the other issue that the BRICS usually touch upon. Disappointing thus far is the near total group silence on international development issues.

\section{Convergence and divergence within the group}

In an honest assessment, differences are substantial: Brazil and India do not want the Chinese Renminbi as a global reserve currency as long as the government in Beijing still has massive influence on the rate of exchange. With regard to the IMF succession after Dominique Strauss-Kahn, input from the BRICS did not exist. They are also very absent with regard to the World Bank succession for June/July this year.

Beijing's approach is more "don't rock the boat" - a very sensible approach when, in 
fact, smooth sailing (to the top of the world economy) is all you aspire to. Chinese interests, it seems, are taken care of by the promotion of high-profile Chinese within existing international organisations. We might still be surprised to see a Chinese chair of the World Bank, as China gains clout without having to make much noise about it (unlike Russia, for instance). A Chinese World Bank President, however, is an issue for the more distant future and other candidates from Brazil or South Africa are not yet in sight. In any case, the BRICS are - for better or worse - not the South-South solidarity steam locomotive that is evoked in Sunday speeches.

A lot of discussion in South Africa was about the decision-making structures, or more specifically, whether South Africa risks being ploughed under by the other, much bigger states. In a mechanism like the BRICS club, that's a nonsensical question: there are no decisions. Just think of the UN Security Council votes on Libya (South Africa in favour, the other BRICS abstaining) or Syria (South Africa in favour, Russia and China blocking by veto). This diverse behaviour (wherever one sides in the individual votes) is not bad in itself, as the common ground for all five countries is very small.

Consequently, it is topic beyond 'high politics' that they should discuss - the BRICS need to get down to earth instead of practicing Sunday speeches. Policies instead of politics, please!

\section{Possible topics: food, trade, energy, finance}

News coverage reported that an expert round made 18 recommendations to the BRICS leaders in areas such as global governance, food and energy security, intraBRICS trade, and academic exchanges. All areas are actually areas for debate; and for debate means that the level of agreement on them is limited thus far. We might see this disagreement as a glass half empty. Yet, differences need to be discussed in order to be able to learn from each other. It is through identifying differences and making mistakes that human learning takes place, not through feel-good discussions.

As reported by several sources, the BRICS group is considering the creation of its own bank and an investment fund to stimulate development in the emerging countries. This could mean create a challenge to the IMF from outside. The IMF is far from sacrosanct, but we need to explore the question of who would benefit from that? Debates seem to be more about funding development in emerging economies, read: BRICS countries themselves. Does India want to lend money to China for its economic rise? Or does South Africa? It might make sense, but the small print is important here! The developmental role has not yet been evoked and is actually taking place in other forums (the G20, for instance).

The potential of the BRICS as a political club has to be judged realistically. But even with these modest expectations: the potential of the BRICS is far from having been tapped into. 